\title{
ALGORITMA BACK PROPAGATION NEURAL NETWORK UNTUK PENGENALAN POLA KARAKTER HURUF JAWA
}

\author{
Nazla Nurmila, Aris Sugiharto, dan Eko Adi Sarwoko \\ Prodi Ilmu Komputer Jurusan Matematika F. MIPA UNDIP
}

\begin{abstract}
Back Propagation Neural Network (BPNN) is a type of algorithm in Neural Network that can be use for Javanese alphabets character recognition. Matlab 7.1 has been used as a software to support the program. The main purpose of this research is order to find out BPNN's training characteristic from each samples. On the other hand, this research also gives BPNN's accurancy value in Javanese alphabets character recognition.

The result of research shows that each part of the samples having different BPNN's characteristic based on the best training.
\end{abstract}

Keywords : NN, BPNN

\section{Pendahuluan}

Seiring dengan berkembangnya teknologi, komputer diharapkan memiliki kemampuan untuk mengerjakan segala sesuatu yang dapat dikerjakan oleh manusia. Agar komputer dapat bertindak seperti dan sebaik manusia, diperlukan beberapa metode untuk membekali komputer agar menjadi mesin yang pintar. Salah satunya yaitu dengan mengimplementasikan Neural Network (NN) pada komputer.

$N N$ merupakan sebuah sistem pembelajaran terhadap penerimaan informasi yang memiliki kinerja layaknya sebuah jaringan syaraf pada manusia. $N N$ diimplementasikan dengan menggunakan program komputer sehingga mampu menyelesaikan sejumlah proses perhitungan. Salah satu penggunaan $N N$ adalah untuk pengenalan pola. Sistem pengenalan pola merupakan komponen penting dalam proses peniruan cara kerja sistem manusia

Dalam pengenalan pola karakter, banyak jenis karakter yang dapat dikenali melalui komputer dengan menggunakan berbagai algoritma. Pada tahun 2005, Reki Zamasari telah berhasil membuat program aplikasi pengenalan pola karakter huruf Jawa dengan algoritma Kohonen Neural Network (KNN). Di tahun yang sama, Agung Nugroho berhasil membuat program aplikasi pengenalan pola karakter huruf Jawa dengan menggunakan algoritma Learning Vector Quantization (LVQ). Algoritma dalam penelitian ini digunakan Back Propagation
Neural Network (BPNN) untuk mengenali pola karakter huruf Jawa.

Karakter huruf Jawa yang terdiri atas 20 merupakan pola karakter kompleks. Hal ini disebabkan karena pola karakter tersebut memiliki banyak kemiripan antar setiap individu karakter.

Untuk mengetahui karakteristik BPNN, pelatihan dilakukan pada masing-masing bagian sampel. Data sampel terbagi atas 6 jenis, yaitu 1 sampel, 3 sampel, 5 sampel, 8 sampel, 10 sampel, dan 15 sampel. Selain itu, penelitian ini juga memberikan nilai keakuratan $B P N N$ dalam mengenali pola karakter huruf Jawa

\section{Tinjauan Pustaka}

\subsection{Neural Network (NN)}

$N N$ adalah prosesor yang terdistribusi paralel, terbuat dari unit-unit yang sederhana, dan memiliki kemampuan untuk menyimpan pengetahuan yang diperoleh secara eksperimental dan siap pakai untuk berbagai tujuan (Rajasekaran, 2005).

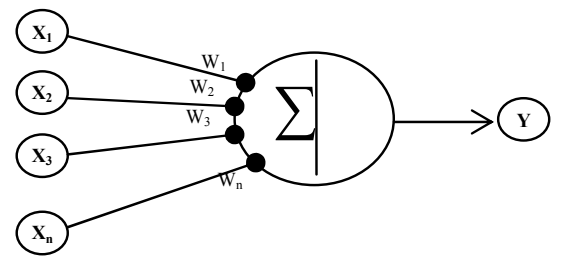

Gambar 1. Proses Komunikasi Antar Neuron 
Pada Gambar 1 diperlihatkan bahwa $N N$ terdiri atas satuan-satuan pemroses berupa neuron. $\mathrm{Y}$ sebagai output menerima input dari neuron $\mathrm{X}_{1}, \mathrm{X}_{2}, \mathrm{X}_{3}, \ldots, \mathrm{X}_{\mathrm{n}}$ dengan bobot $\mathrm{W}_{1}, \mathrm{~W}_{2}$, $\mathrm{W}_{3}, \ldots, \mathrm{W}_{\mathrm{n}}$. Hasil penjumlahan seluruh impuls neuron dibandingkan dengan nilai ambang tertentu melalui fungsi aktivasi $f$ setiap neuron. Fungsi aktivasi digunakan sebagai penentu keluaran suatu neuron.

Salah satu metode pelatihan dalam $N N$ adalah pelatihan terbimbing (supervised learning). Pada pelatihan terbimbing diperlukan sejumlah masukan dan target yang berfungsi untuk melatih jaringan hingga diperoleh bobot yang diinginkan.

Pada setiap kali pelatihan, suatu input diberikan ke jaringan. Jaringan akan memproses dan mengeluarkan keluaran. Selisih antara keluaran jaringan dengan target merupakan kesalahan yang terjadi. Jaringan akan memodifikasi bobot sesuai dengan kesalahan tersebut. BPNN merupakan metode yang menggunakan supervised learning.

\subsection{Back Propagation Neural Network (BPNN)}

$B P N N$ merupakan algoritma pelatihan terbimbing yang mempunyai banyak lapisan. BPNN menggunakan error output untuk mengubah nilai bobot-bobotnya dalam arah mundur (backward). Untuk mendapatkan error ini, tahap perambatan maju (forward propagation) harus dikerjakan terlebih dahulu.
Syarat fungsi aktivasi dalam $B P N N$ adalah bersifat kontinu, terdifferensial dengan mudah, dan merupakan fungsi yang tidak turun. Fungsi aktivasi yang dapat memenuhi ketiga syarat tersebut adalah logsig, tansig, dan purelin.

Metode pengenalan merupakan proses inisialisasi data yang akan diolah selanjutnya oleh BPNN. Data yang akan dikenali disajikan dalam bentuk vektor. Masing-masing data mempunyai target yang disajikan juga dalam bentuk vektor. Target atau keluaran acuan merupakan suatu peta karakter yang menunjukkan lokasi dari vektor masukan.

Sedangkan metode pelatihan merupakan proses latihan mengenali data dan menyimpan pengetahuan atau informasi yang didapat ke dalam bobot-bobot (Heaton, 2003).

Terdapat 3 fase dalam pelatihan BPNN, yaitu fase maju (feed forward), fase mundur (back propagation), dan fase modifikasi bobot. Dalam fase feed forward, pola masukan dihitung maju dimulai dari lapisan input hingga lapisan output. Dalam fase back propagation, tiap-tiap unit output menerima target pola yang berhubungan dengan pola input untuk dihitung nilai kesalahan. Kesalahan tersebut akan dipropagasikan mundur. Sedangkan fase modifikasi bobot bertujuan untuk menurunkan kesalahan yang terjadi. Ketiga fase tersebut diulang secara terus menerus hingga kondisi penghentian dipenuhi.

Berikut ini merupakan algoritma dalam pelatihan BPNN (Kusumadewi, 2004) :

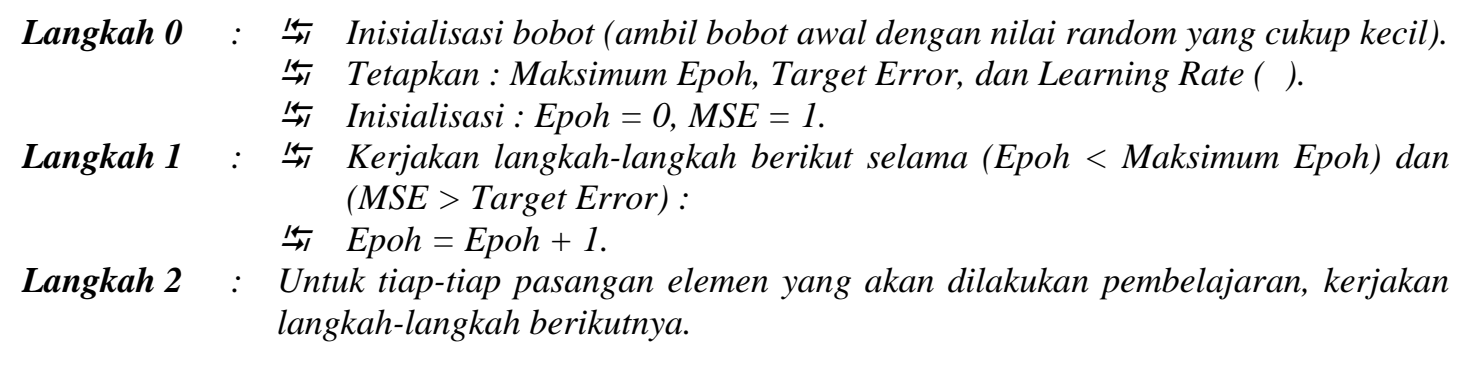

Fase I : Feed Forward 
Langkah 3 : Tiap-tiap unit input $\left(X_{i}, i=1,2, \ldots, n\right)$ menerima sinyal $X_{i}$ dan meneruskan sinyal tersebut ke semua unit pada lapisan yang ada di atasnya (lapisan tersembunyi).

Langkah 4 : Tiap-tiap unit pada suatu lapisan tersembunyi $\left(Z_{j}, j=1,2, \ldots, p\right)$ menjumlahkan sinyal-sinyal input terbobot :

$z_{-i n} n_{j}=b 1_{j}+\sum_{i=1}^{n} x_{i} v_{i j}$

gunakan fungsi aktivasi untuk menghitung sinyal output :

$Z_{j}=f\left(Z_{-} i n_{j}\right)$

dan kirimkan sinyal tersebut ke semua unit di lapisan atasnya (unit-unit output).

Langkah 5 : Tiap-tiap unit output $Y_{k}(k=1,2, \ldots, m)$ menjumlahkan sinyal-sinyal input terbobot

$Y_{-} m_{k}=b 2_{k}+\sum_{i=1}^{p} Z_{i} w_{k}$

gunakan fungsi aktivasi untuk menghitung sinyal output :

$Y_{k i}=f\left(Y_{-} m_{h i}\right)$

dan kirimkan sinyal tersebut ke semua unit di lapisan atasnya (unit-unit output).

\section{Fase II : $\quad$ Back Propagation}

Langkah $6:$ : $\quad \stackrel{\leftrightarrow}{\rightarrow}$ Tiap-tiap unit output $Y_{k}(k=1,2, \ldots, m)$ menerima target pola yang berhubungan dengan pola input pelatihan, hitung informasi errornya :

$\delta=\left(t_{k}-Y_{k}\right) f^{f}\left(Y_{-} m_{h}\right)$

$\varphi 2_{j k}=\delta_{k i} Z_{j}$

$\rho 2_{\overline{7 i}}=S_{\overline{7 i}}$

$\leftrightarrow$ Kemudian hitung koreksi bobot (yang nantinya akan digunakan untuk memperbaiki nilai ):

$\Delta W_{j k}=\alpha \varphi 2_{j k}$

$\leftrightarrow$ Hitung juga koreksi bias (yang nantinya akan digunakan untuk memperbaiki nilai ):

$\Delta b 2_{\bar{h}}=\alpha \beta 2_{\overline{k i}}$

Langkah $7: \stackrel{\leftrightarrow}{\rightarrow}$ Tiap-tiap unit tersembunyi $Z_{j}(j=1,2, \ldots, p)$ menjumlahkan delta inputnya (dari unit-unit yang berada pada lapisan di atasnya :

$\delta i m_{j}=\sum_{k=1}^{m} \delta 2_{k} W_{j k}$

$\stackrel{\leftrightarrow}{\rightarrow}$ Kalikan nilai ini dengan turunan dari fungsi aktivasinya untuk menghitung informasi error :

$\delta 1_{j}=\varepsilon_{-} i_{j} f^{\prime}\left(z_{-} i_{j}\right)$

$\varphi 1_{i j}=51_{j} X_{i}$

$\beta 1_{j}=\delta 1_{j}$

$\leftrightarrow$ Kemudian hitung koreksi bobot (yang nantinya akan digunakan untuk memperbaiki nilai :

$\Delta V_{i j}=\alpha \omega 1_{i j}$

$\stackrel{\leftrightarrow}{\rightarrow}$ Hitung juga koreksi bias (yang nantinya akan digunakan untuk memperbaiki nilai ):

$\Delta b 1_{j}=\alpha \beta 1_{j}$ 


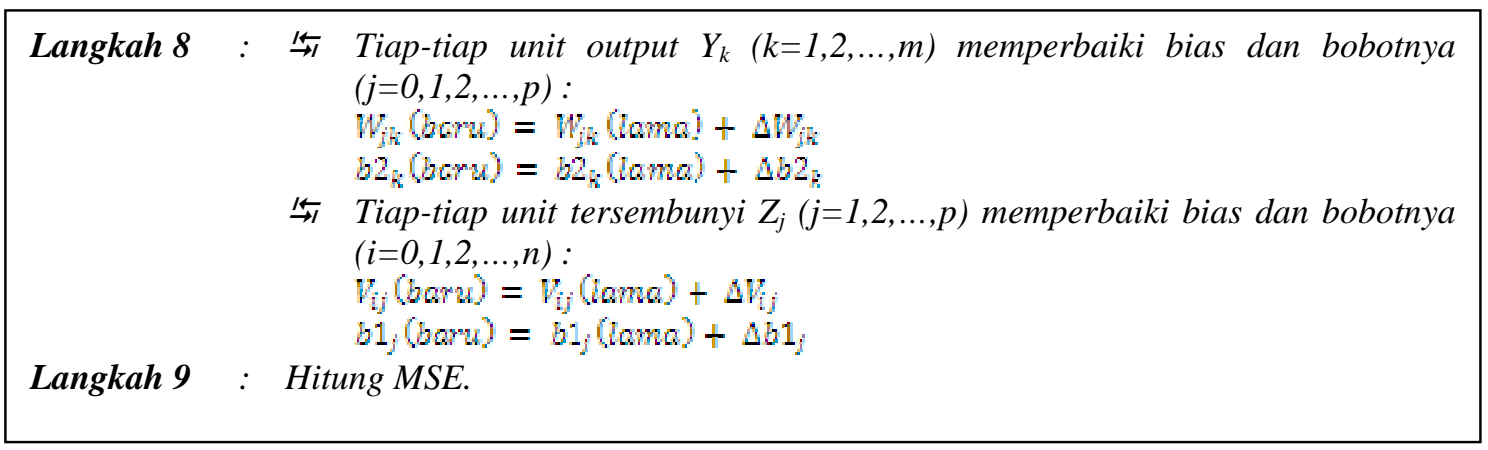

\subsection{Pemrograman BPNN dengan Matlab} 7.1

Matlab 7.1 mempunyai toolbox $N N$ yang dapat digunakan dalam menyelesaikan permasalahan BPNN. Untuk menginisialisasi jaringan, perintah yang digunakan adalah newff. Format yang diberikan oleh toolbox Matlab 7.1 adalah sebagai berikut :

net=newff $(\operatorname{minmax}(\mathrm{P}),[\mathrm{S} 1 \mathrm{~S} 2 \ldots \mathrm{SN}],\{\mathrm{TF} 1$ TF2...TFN $\}, B T F, B L F, P F)$

Setiap kali membentuk jaringan, Matlab 7.1 akan memberikan nilai bobot awal dengan bilangan random kecil. Bobot akan berubah setiap kali menginisialisasi jaringan. Akan tetapi, jika diinginkan memberi bobot tertentu, dapat menggunakan perintah net.IW $\{i, j\}$ dan net.LW $\{\mathrm{j}, \mathrm{k}\}$.

Setelah menginisialisasi jaringan dan bobot, hasilnya kemudian disimulasikan dengan input yang sama dengan input data pelatihan. Simulasi jaringan merupakan proses untuk menghitung keluaran jaringan. Perintah sim dalam Matlab 7.1 dapat digunakan untuk melakukan simulasi. Formatnya adalah $\mathrm{Y}=\operatorname{sim}($ net, $\mathrm{P})$ Sedangkan untuk melakukan pelatihan BPNN, digunakan fungsi train yang formatnya adalah net $=$ train (net, $\mathrm{P}, \mathrm{T}$ )

\section{Pembahasan dan Hasil Penelitian}

\subsection{Persiapan Data Pelatihan}

Data pelatihan yang digunakan terbagi atas 6 bagian. Masing-masing bagian menunjukkan banyaknya jumlah sampel pola. Tujuan dari pembagian data pelatihan agar dapat membandingkan hasil pelatihan pada masingmasing bagian. Selain itu, untuk membandingkan nilai keakuratan proses pengujian berdasarkan hasil pelatihan. Keenam bagian tersebut akan ditunjukkan dalam Tabel 1 .

Tabel 1. Pembagian Data Pelatihan

\begin{tabular}{||c|c|c|c|c|c|c|c|c|c|c|c|c|c|c|c|c||}
\hline \multirow{2}{*}{ No. } & \multirow{10}{*}{ Bagian } & \multicolumn{10}{|c||}{ Sampel ke - } \\
\hline & & $\mathbf{1}$ & $\mathbf{2}$ & $\mathbf{3}$ & $\mathbf{4}$ & $\mathbf{5}$ & $\mathbf{6}$ & $\mathbf{7}$ & $\mathbf{8}$ & $\mathbf{9}$ & $\mathbf{1 0}$ & $\mathbf{1 1}$ & $\mathbf{1 2}$ & $\mathbf{1 3}$ & $\mathbf{1 4}$ & $\mathbf{1 5}$ \\
\hline \hline 1. & 1 Sampel & $\sqrt{ }$ & & & & & & & & & & & & & & \\
\hline 2. & 3 Sampel & $\sqrt{ }$ & $\sqrt{ }$ & $\sqrt{ }$ & & & & & & & & & & & & \\
\hline 3. & 5 Sampel & $\sqrt{ }$ & $\sqrt{ }$ & $\sqrt{ }$ & $\sqrt{ }$ & $\sqrt{ }$ & & & & & & & & & & \\
\hline 4. & 8 Sampel & $\sqrt{ }$ & $\sqrt{ }$ & $\sqrt{ }$ & $\sqrt{ }$ & $\sqrt{ }$ & $\sqrt{ }$ & $\sqrt{ }$ & $\sqrt{ }$ & & & & & & & \\
\hline 5. & 10 Sampel & $\sqrt{ }$ & $\sqrt{ }$ & $\sqrt{ }$ & $\sqrt{ }$ & $\sqrt{ }$ & $\sqrt{ }$ & $\sqrt{ }$ & $\sqrt{ }$ & $\sqrt{ }$ & $\sqrt{ }$ & & & & & \\
\hline 6. & 15 Sampel & $\sqrt{ }$ & $\sqrt{ }$ & $\sqrt{ }$ & $\sqrt{ }$ & $\sqrt{ }$ & $\sqrt{ }$ & $\sqrt{ }$ & $\sqrt{ }$ & $\sqrt{ }$ & $\sqrt{ }$ & $\sqrt{ }$ & $\sqrt{ }$ & $\sqrt{ }$ & $\sqrt{ }$ & $\sqrt{ }$ \\
\hline
\end{tabular}

3.2. Pengolahan Citra

Pola karakter yang digunakan seringkali memiliki tingkat kualitas yang rendah sehingga 
tidak dapat menghasilkan suatu output yang dikenali dengan baik oleh komputer. Agar pola karakter dapat direpresentasikan dengan baik, proses pengolahan citra dapat digunakan untuk memperbaiki kualitas citra. Selain itu, untuk dapat diproses oleh $B P N N$, data pelatihan yang digunakan harus memiliki tipe citra dan ukuran pixel yang sama.

Tahap-tahap dan contoh pada proses pengolahan citra yang digunakan dalam merepresentasikan pola karakter huruf Jawa terlihat pada Gambar 2 dan Gambar 3.

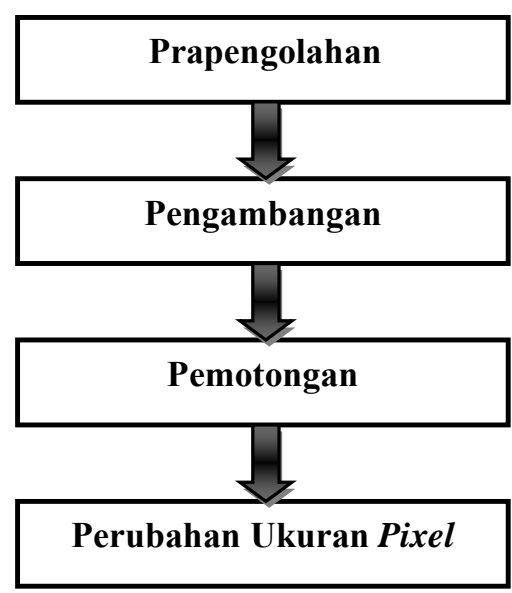

Gambar 2. Tahap-Tahap Proses Pengolahan Citra
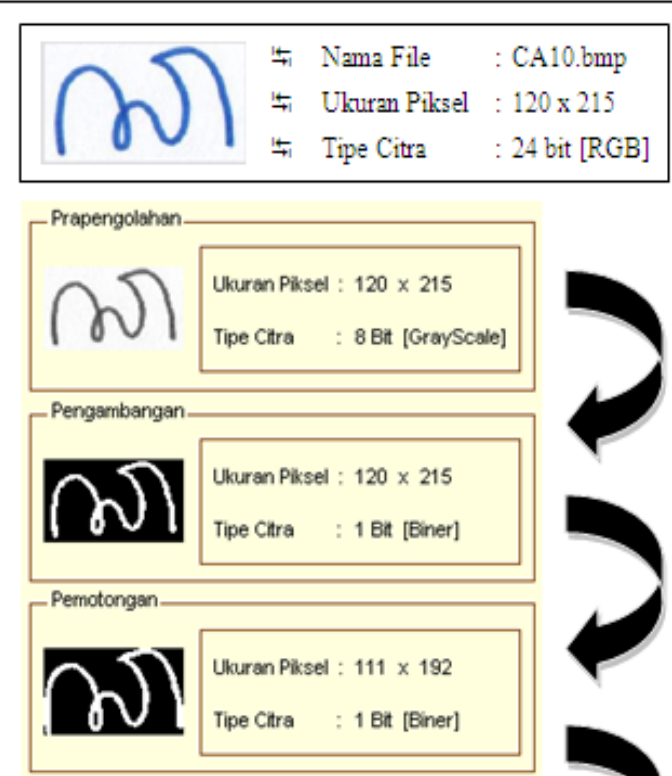

Perubahan Ulkuran

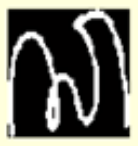

Ukuran Piksel : $80 \times 80$

Tipe Citra : 1 Bit [Biner]

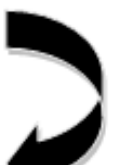

Gambar 3. Contoh Proses Pengolahan Citra Pola Karakter Huruf Jawa

\subsection{Pelatihan Pola Karakter Huruf Jawa dengan BPNN}

Pelatihan pola karakter huruf Jawa dilakukan secara berulang-ulang dengan menggunakan data pelatihan, jumlah neuron dan parameter jaringan berupa learning rate dan momentum yang berbeda-beda. Sedangkan untuk fungsi pelatihan, fungsi evaluasi, fungsi aktivasi, dan parameter jaringan lainnya selain learning rate dan momentum bersifat tetap.

Tujuan dari pelatihan yang berulang-ulang ini adalah untuk mendapatkan karakteristik BPNN yang terbaik sehingga BPNN tersebut dapat mempelajari pola yang diberikan dengan baik.

Adapun batasan-batasan dalam melakukan pelatihan pola karakter huruf Jawa ini antara lain adalah :

1. Data pelatihan menggunakan 1 sampel, 3 sampel, 5 sampel, 8 sampel, 10 sampel, dan 15 sampel. 
2. Fungsi pelatihan yang digunakan adalah traingdx.

3. Fungsi evaluasi yang digunakan adalah sse.

4. Banyaknya jumlah neuron yang digunakan adalah 5, 15, dan 25.

5. Fungsi aktivasi yang digunakan pada lapisan tersembunyi dan lapisan output kedua-duanya adalah logsig.

6. Jumlah epoh maksimum adalah 3000 .

7. Pilihan untuk nilai learning rate adalah $0.01,0.03$, dan 0.05 .

8. Nilai momentum yang digunakan adalah $0.5,0.7$, dan 0.9

9. Nilai yang diberikan untuk kenaikan dan penurunan learning rate masing-masing adalah 1.05 dan 0.7 .

10.Proses pelatihan dihentikan apabila sudah tercapai goal yang diinginkan, yaitu 0.1 .

11.Untuk setiap data pelatihan dilakukan beberapa kali pelatihan dan diambil 1 yang terbaik untuk dijadikan sebagai acuan proses pengujian.

12.Hasil terbaik dari pelatihan ditentukan berdasarkan nilai squared error terkecil dan berakhir epoh yang paling kecil.

\subsection{Pengujian Hasil Pelatihan}

Langkah pertama dalam melakukan proses pengujian adalah mempersiapkan data pengujian. Data pengujian tersusun atas 20 kelas pola karakter huruf Jawa. Masing-masing kelas mempunyai 15 sampel pola. Sehingga terdapat 300 pola yang digunakan untuk mempersiapkan data pengujian. Data pelatihan yang telah terbagi atas 6 bagian dan masing-masing telah memiliki hasil pelatihan akan diikut sertakan dalam mempersiapkan data pengujian.

Langkah kedua adalah menentukan pola karakter yang akan diuji. Dalam hal ini, tidak ada aturan khusus dalam menentukan pola karakter mana yang akan diuji terlebih dahulu.

Langkah selanjutnya adalah proses pengolahan citra. Proses yang dilakukan yaitu prapengolahan, pengambangan, pemotongan, dan perubahan ukuran pixel.

Sedangkan proses pengenalan pola merupakan proses untuk menentukan nilai keakuratan BPNN dalam mengenali pola karakter huruf Jawa. Pola karakter berupa data pengujian akan disimulasikan berdasarkan hasil pelatihan. Pola karakter yang memiliki nilai simulasi terbesar merupakan pola karakter yang dikenali oleh BPNN.

Tabel 2 merupakan tabel seluruh hasil pengujian. 
Tabel 2. Nilai Keakuratan Pengujian Pola Karakter Huruf Jawa

\begin{tabular}{|c|c|c|c|c|c|c|}
\hline \multirow{2}{*}{ No. } & \multicolumn{7}{|c|}{ Nilai Keakuratan (\%) } \\
\cline { 2 - 7 } & $\mathbf{1}$ sampel & 3 sampel & 5 sampel & 8 sampel & 10 sampel & 15 sampel \\
\hline \hline 1. & 100 & 100 & 100 & 100 & 100 & 100 \\
\hline 2. & 10 & 100 & 100 & 100 & 100 & 100 \\
\hline 3. & 0 & 100 & 100 & 95 & 95 & 95 \\
\hline 4. & 5 & 55 & 100 & 100 & 100 & 100 \\
\hline 5. & 30 & 25 & 100 & 100 & 95 & 100 \\
\hline 6. & 10 & 50 & 55 & 100 & 100 & 100 \\
\hline 7. & 15 & 50 & 50 & 100 & 100 & 95 \\
\hline 8. & 5 & 35 & 50 & 100 & 100 & 100 \\
\hline 9. & 5 & 80 & 85 & 85 & 100 & 100 \\
\hline 10. & 15 & 70 & 70 & 90 & 100 & 100 \\
\hline 11. & 100 & 90 & 100 & 95 & 100 & 100 \\
\hline 12. & 5 & 40 & 45 & 70 & 80 & 100 \\
\hline 13. & 10 & 70 & 90 & 90 & 100 & 100 \\
\hline 14. & 15 & 65 & 75 & 85 & 75 & 95 \\
\hline 15. & 15 & 55 & 30 & 70 & 65 & 100 \\
\hline $\begin{array}{c}\text { Rata-Rata Data } \\
\text { Pelatihan }\end{array}$ & 100 & 100 & 100 & 99.375 & 99 & 99 \\
\hline $\begin{array}{c}\text { Rata-Rata Diluar } \\
\text { Data Pelatihan }\end{array}$ & 17.143 & 57.083 & 65 & 83.571 & 84 & - \\
\hline Data Seluruh & 22.667 & 65.667 & 76.667 & 92 & 94 & 99 \\
\hline \hline
\end{tabular}

Terlihat pada Tabel 2, sampel yang diarsir warna biru merupakan data pengujian yang digunakan pada saat melakukan proses pelatihan. Dengan kata lain, arsiran warna biru pada Tabel 2 menunjukkan banyaknya sampel yang digunakan pada saat pelatihan.

\subsection{Analisis Hasil Pelatihan dan Pengujian Pola Karakter Huruf Jawa}

Terdapat 6 bagian dalam pelatihan pola karakter huruf Jawa. Masing-masing bagian memiliki karakteristik BPNN yang berbedabeda. Hasil pelatihan yang ditunjukkan mempunyai nilai yang berbeda-beda pula. Berdasarkan hasil pelatihan tersebut, diambil 1 yang terbaik untuk dijadikan sebagai acuan proses pengujian. Seluruh karakteristik BPNN dengan hasil pelatihan terbaik pada masingmasing bagian sampel beserta hasil pengujiannya ditunjukkan dalam Tabel 3 . 
Tabel 3. Karakteristik Pelatihan BPNN Terbaik dan Hasil Pengujian

\begin{tabular}{||c|c|c|c|c|c|c|c||}
\hline \multirow{2}{*}{ No. } & $\begin{array}{c}\text { Data } \\
\text { Sampel } \\
\text { (i) }\end{array}$ & $\begin{array}{c}\text { Jumlah } \\
\text { Neuron }\end{array}$ & LR & Momentum & $\begin{array}{c}\text { Data } \\
\text { Pelatihan } \\
\text { (Data } \\
\text { Sampel i) }\end{array}$ & $\begin{array}{c}\text { Di luar Data } \\
\text { Pelatihan } \\
\text { (Data Sampel } \\
\text { i+1 s/d 15) }\end{array}$ & $\begin{array}{c}\text { Seluruh Data } \\
\text { (Data Sampel } \\
\text { 1 s/d 15) }\end{array}$ \\
\hline \hline 1. & 1 Sampel & 25 & 0.03 & 0.7 & 100 & 17.143 & 22.667 \\
\hline 2. & 3 Sampel & 15 & 0.01 & 0.5 & 100 & 57.083 & 65.667 \\
\hline 3. & 5 Sampel & 15 & 0.03 & 0.9 & 100 & 65 & 76.667 \\
\hline 4. & 8 Sampel & 25 & 0.01 & 0.5 & 99.375 & 83.571 & 92 \\
\hline 5. & 10 Sampel & 15 & 0.01 & 0.5 & 99 & 84 & 94 \\
\hline 6. & 15 Sampel & 25 & 0.01 & 0.5 & 99 & - & 99 \\
\hline \hline
\end{tabular}

Berdasarkan Tabel 3, dapat ditunjukkan bahwa :

1. Masing-masing bagian sampel memiliki karakteristik BPNN yang berbeda-beda untuk mendapatkan hasil pelatihan yang paling baik.

2. Semakin banyak data pelatihan, semakin baik nilai keakuratan BPNN dalam mengenali seluruh pola karakter huruf Jawa, baik data pelatihan yang ikut diuji maupun yang tidak ikut diuji.

Hal ini terlihat pada rata-rata nilai keakuratan seluruh data pengujian yang bernilai $22.667 \%, 65.667 \%, 76.667 \%, 92 \%$, $94 \%$, dan $99 \%$.

3. Semakin banyak data pelatihan, semakin kecil nilai keakuratan BPNN dalam mengenali dirinya sendiri. Data pengujian ini merupakan data pelatihan. Akan tetapi, nilai keakuratan tersebut tidak menunjukkan hasil yang terlalu signifikan.

Hal ini terlihat pada rata-rata nilai keakuratan data pelatihan yang bernilai $100 \%, 100 \%, 100 \%, 99.375 \%$, 99\%, dan $99 \%$.

4. Semakin banyak data pelatihan, semakin baik BPNN mengenali pola karakter huruf Jawa yang tidak ikut dilatih dalam proses pelatihan.

Hal ini terlihat pada rata-rata nilai keakuratan di luar data pelatihan yang memberikan $17.143 \%, \quad 57.083 \%, \quad 65 \%$, $83.571 \%$, dan $84 \%$.

\section{Kesimpulan}

Penelitian ini menunjukkan bahwa masingmasing bagian sampel memiliki karakteristik $B P N N$ yang berbeda-beda untuk mendapatkan hasil pelatihan yang paling baik.

Sedangkan rata-rata keakuratan $B P N N$ dalam mengenali pola karakter huruf Jawa adalah sebesar $99.563 \%$ untuk data sampel berupa data pelatihan, $61.359 \%$ untuk data sampel diluar data pelatihan, dan $75 \%$ untuk data sampel data pelatihan dan di luar data pelatihan.

\section{Daftar Pustaka}

[1] P. Nugraha dan A. B. Mutiara, "Metode Ekstraksi Data untuk Pengenalan Huruf dan angka Tulisan Tangan dengan Menggunakan Jaringan Syaraf Buatan Propagasi Balik“, http://www.gunadarma.ac.id, 2004. (diakses terakhir pada tanggal 12 Maret 2007 jam 15.56 WIB).

[2] Heaton, J., "Introduction to Neural Network with Java”, http://www.heatonresearch.com/articles/6/p age2.html, 2003. (diakses terakhir pada tanggal 28 Agustus 2007 jam 14.35 WIB). Kusumadewi, Sri, "Artificial Intelligence 
(Teknik dan Aplikasinya)", Graha Ilmu, Yogyakarta, 2003.

[3] Kusumadewi, Sri, "Membangun Jaringan Syaraf Tiruan Menggunakan MATLAB \& EXCEL LINK”, Graha Ilmu, Yogyakarta, 2004.

[4] Munir, Rinaldi, "Pengolahan Citra Digital dengan pendekatan algoritmik", Informatika, Bandung, 2004.

[5] Murni, Aniati, "Pengantar Pengolahan Citra", Elex Media Komputindo, Jakarta, 1992.

[6] Nugroho, Agung, "Pengenalan Pola Karakter Huruf Jawa menggunakan Jaringan Syaraf Tiruan LVQ (Learning Vector Quantization)", Tugas AkhirPerpustakaan F. MIPA UNDIP, Semarang, 2005.

[7] Nur Yusuf Oktavia, Ahmad Zakky, Riyanto Sigit, Miftahul Huda, "Aplikasi Jaringan Syaraf Tiruan untuk Pengenalan Huruf pada Pengolahan Citra Digital Berbasis Web”, Makalah Tugas Pendahuluan Proyek Akhir, Politeknik Elektronika Negeri Surabaya-Institut Teknologi Sepuluh Nopember Surabaya, 2002.

[8] Prabowo, Anindito, "Perbandingan antara Metode Kohonen Neural Network dengan Metode Learning Vector Quantization pada
Pengenalan Pola Tandatangan”, Tugas Akhir-Perpustakaan F. MIPA UNDIP, Semarang, 2007.

[9] Rajasekaran S.,GA. Vijayalakshmi Pai, "Neural Network, Fuzzy Logic and Genetic Algorithms", Prentice-Hall of India, New Delhi, 2005.

[10] Samudera, Istyawan, "Pencocokan Citra Sidik Jari dengan Jaringan Syaraf Tiruan Back Propagation dan Wavelet menggunakan GUI Matlab 6.5”, Tugas Akhir-Perpustakaan F. MIPA UNDIP, Semarang, 2005.

[11] Siang, Jong Jek, “Jaringan Syaraf Tiruan dan Pemrogramannya menggunakan Matlab”, Andi, Yogyakarta, 2005.

[12] Sugiharto, Aris, "Pemrograman GUI dengan MATLAB”, Andi, Yogyakarta, 2006.

[13] Zamasari, Reki, "Pengenalan Pola Karakter Aksara Jawa dengan Algoritma Kohonen Neural Network", Tugas AkhirPerpustakaan F. MIPA UNDIP, Semarang, 2005.

[14] www.mathworks.com (diakses terakhir pada tanggal 23 September 2007 jam 15.25 WIB). 
